\title{
Perencanaan Kebutuhan Pengembangan Sistem Informasi
}

\section{(Studi Kasus : Perpustakaan Daerah Kota XYZ)}

\author{
Paramita Mayadewi ${ }^{1}$ \\ ${ }^{1}$ Program Studi Manajemen Informatika \\ Fakultas Ilmu Terapan Universitas Telkom \\ Jalam Telekomunikasi Terusan Buah Batu Bandung 40257 \\ 1 paramita@tass.telkomuniversity.ac.id
}

\begin{abstract}
Abstrak - Perpusda Kota XYZ merupakan organisasi nirlaba yang memberikan layanan kepada masyarat dengan menyediakan buku-buku sebagai sumber informasi. Dalam pencapaian tujuan Perpusda Kota XYZ untuk mewujudkan penyelenggaraan Perpusda sebagai pusat kegiatan belajar masyarakat serta sebagai sarana sumber informasi, diperlukan rencana sistem informasi yang sejalan dengan tujuan organisasi. Kegagalan implementasi sistem informasi dalam organisasi sering terjadi akibat ketidaksesuaian sistem informasi dengan tujuan dan sasaran bisnis organisasi mereka. Penelitian ini bertujuan untuk merencanakan strategi pengembangan sistem informasi bagi Perpusda Kota XYZ utuk mengidentifkasi kebutuhan aplikasi yang diperlukan yang dapat mendukung tujuan organisasi. Perencanaan strategi dilakukan dengan menggunakan tools analisis seperti analisis PEST, SWOT, Value Chain, dan Business System Planning.
\end{abstract}

Kata Kunci - sistem informasi, strategi pengembangan, kebutuhan aplikasi

Abstract - XYZ's regional library is a non profit organization that provides services to the community by providing books as information resources. In achieving their goal to realize the implementation of the regional library as learning center as well as a means of information resources, it need information system plan in line with organizational goals. Failure of information systems implementation in organizations often occurs due to a mismatch of information systems with business goals and objectives of their organization. This study aims to plan XYZ's regional library information system strategy plan to identify the need of application that required to support organizational goals. Strategic planning is done by using analysis tools such as PEST analysis, SWOT, Value Chain and Business Systems Planning.

Keyword: information system, strategy development, application needs

\section{PENDAHULUAN}

Perpustakaan Daerah (perpusda) Kota XYZ merupakan organisasi nirlaba/non-profit yang dibentuk oleh Pemerintah Daerah untuk memberikan pelayanan kepada masyarakat, yaitu dengan menyediakan buku-buku sebagai sumber informasi yang sangat diperlukan oleh masyarakat daerah dan diluar daerah tersebut. Dalam upaya memenuhi misinya, Perpusda Kota XYZ memerlukan keterpaduan arah agar dapat menerapkan langkahlangkah yang efektif dan pemanfaatan sumber daya yang efisien, yang diformulasikan dalam strategi organisasi. Salah satu strategi yang semakin banyak diterapkan adalah dengan memanfaatkan sistem informasi (SI) - dengan teknologi informasi (TI) sebagai pendukung untuk mendukung fungsi bisnis dan perkembangan organisasi.

Saat ini, pemanfaatan dan pengelolaan teknologi informasi pada perpusda kota XYZ belum mengacu pada suatu rencana pemanfaatan SI/TI yang terpadu dan menyeluruh. Karena hal tersebutlah, maka diperlukan suatu perencanaan strategi pengembangan sistem informasi yang bertujuan untuk menetapkan suatu strategi sistem informasi dalam sebuah organisasi, dengan tujuan agar dapat mengidentifikasi aplikasi apa saja yang diperlukan (portofolio aplikasi).

Ruang lingkup penelitian dibatasi pada proses utama perpustakaan. Proses analisa dilakukan secara top-down yaitu mulai dari mengevaluasi visi dan misi perusahaan, analisis lingkungan internal dan eksternal dengan menggunakan analisis PEST dan SWOT, pemetaan proses bisnis dengan menggunakan Value Chain, identifikasi data serta analisis Critical Success Factor (CSF) yang diturunkan dari sasaran organisasi.

Hasil analisa adalah berupa usulan arsitektur informasi perusahaan, khsususnya yang mendukung proses layanan perpustakaan.

\section{A. Analisis PEST dan Analisis SWOT}

Analisis PEST (Politik, Ekonomi, Sosial, Teknologi) adalah analisis terhadap faktor lingkungan eksternal bisnis yang meliputi bidang politik, ekonomi, 
sosial dan teknologi [1]. PEST digunakan untuk menilai pasar dari suatu unit bisnis atau organisasi. Arah analisis PEST adalah kerangka untuk menilai sebuah situasi dan menilai strategi atau posisi serta arah perusahaan.

Analisis SWOT (strengths, weaknesses, opportunities, threats) merupakan suatu metode penyusunan strategi perusahaan atau organisasi [1]. Dalam Analisis SWOT, berbagai faktor diidentifikasi secara sistematis untuk merumuskan strategi perusahaan. Analisa ini didasarkan pada hubungan atau interaksi antara unsur-unsur internal,yaitu kekuatan dan kelemahan, terhadap unsur-unsur eksternal yaitu peluang dan ancaman.

\section{B. Analisis Value Chain}

Analisis Value Chain (Rantai Nilai), merupakan alat analisis yang berguna untuk memahami aktivitasaktivitas yang membentuk nilai suatu produk atau jasa dan digunakan untuk menciptakan nilai bagi pelanggannya dalam mencapai suatu keunggulan yang kompetitif [2]. Analisis value chain membantu perusahaan dalam mengidentifikasi posisi perusahaan dan menganalisis aktivitas-aktivitas yang ada dalam rantai nilai serta mengurangkan atau mengeliminasi aktivitas yang tidak menciptakan nilai tambah pada produk atau jasa.

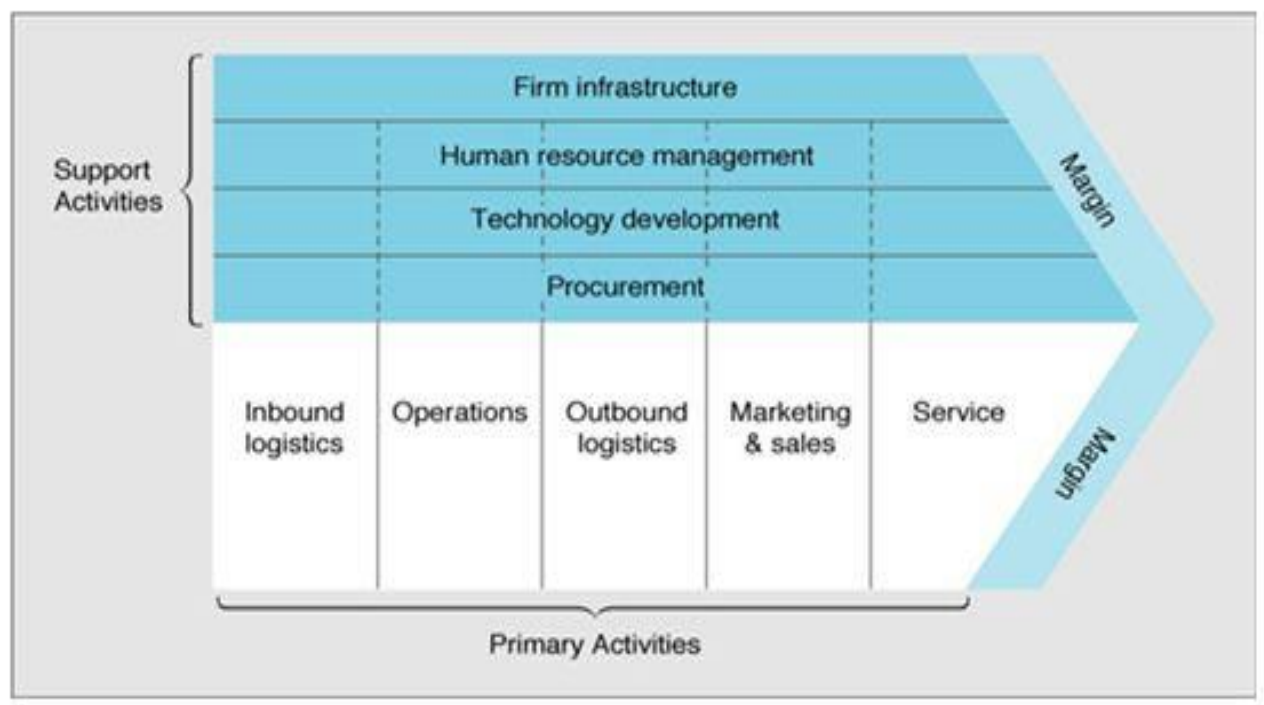

Gambar 1. Value Chain (Rantai Nilai) Porter [2]

Value chain terdiri dari sekumpulan aktivitas utama dan pendukung [2]. Aktivitas pendukung terdiri dari infrastruktur perusahaan, pengelolaan sumber daya manusia, pengembangan teknologi dan usaha memperolehnya. Sedangkan dalam aktivitas utama terdiri dari logistik masuk (inbound logistics), operasi (operations), logistik keluar (outbound logistics), pemasaran dan penjualan (marketing \& sales) serta pelayanan (service), seperti yang terlihat pada gambar 1.

\section{Business System Planning}

Business System Planning (BSP) merupakan pendekatan terstruktur untuk membantu organisasi menetapkan rencana sistem informasi yang dapat mendukung bisnis dan informasi yang dibutuhkan untuk jangka panjang [3].

BSP merupakan proses untuk mentranslasikan strategi bisnis menjadi strategi sistem informasi seperti yang terlihat dalam Gambar 2.

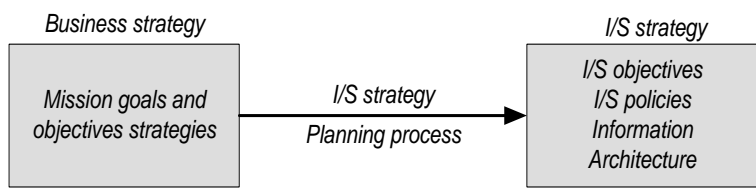

Gambar 2. Translasi dari strategi bisnis ke strategi sistem informasi [3]

\section{Analisis Critical Success Factor (CSF)}

CSF merupakan sebuah metode analisis dengan mempertimbangkan beberapa hal kritis di dalam lingkungan perusahaan untuk mendefinisikan faktorfaktor apa saja yang mempengaruhi keberhasilan dan kesuksesan perusahaan atau organisasi dan dapat ditentukan jika obyektif organisasi telah diidentifikasi [1].

Analisis CSF memberikan gambaran pada perusahaan tentang aspek-aspek kritis apa saja di setiap aktivitas dan proses bisnis perusahaan yang mempengaruhi kinerja perusahaan dalam mencapai visi dan misi serta keberhasilan bisnisnya. Tujuan dari CSF adalah menginterpretasikan obyektif secara lebih jelas untuk menentukan aktivitas yang harus dilakukan dan informasi apa yang dibutuhkan.

\section{E. Portofolio Aplikasi}

Portofolio aplikasi merupakan sebuah model perkiraan kebutuhan sistem aplikasi yang didasarkan pada kebutuhan bisnis disertai dengan definisi apa dan bagaimana sistem aplikasi tersebut memberikan kontribusinya terhadap usaha-usaha pencapaian tujuan bisnis organisasi.

Gambar 3, merupakan diagram matriks portofolio aplikasi yang terdiri dari empat kuadran, yaitu strategic, key operational, support dan high potential 
[1]. Keempat kuadran perkiraan kebutuhan aplikasi

organisasi. ini, didasarkan kepada kontribusinya terhadap bisnis

\begin{tabular}{|c|c|}
\hline Strategic & High Potential \\
\hline $\begin{array}{c}\text { Merupakan aplikasi-aplikasi yang } \\
\text { bersifat kritis untuk menunjang } \\
\text { perkembangan strategi bisnis } \\
\text { organisasi dimasa yang akan } \\
\text { datang. }\end{array}$ & $\begin{array}{c}\text { Merupakan aplikasi-aplikasi yang } \\
\text { mungkin dibutuhkan oleh } \\
\text { organisasi untuk keberhasilan } \\
\text { dimasa yang akan datang, namun } \\
\text { belum dibuktikan. }\end{array}$ \\
\hline Key Operational & Support \\
\hline $\begin{array}{c}\text { Merupakan aplikasi-aplikasi } \\
\text { yang pada saat ini } \\
\text { digunakan oleh organisasi } \\
\text { dalam menjalankan aktivitas } \\
\text { bisnisnya. }\end{array}$ & $\begin{array}{c}\text { Merupakan aplikasi-aplikasi } \\
\text { yang bersifat valuable tetapi } \\
\text { tidak kritis. }\end{array}$ \\
\hline
\end{tabular}

\section{METODOLOGI}

Gambar 3. Matriks Portofolio Aplikasi [1]

Dalam melakukan perencanaan kebutuhan pengembangan sistem informasi pada perpusda kota XYZ, digunakan metodologi BSP yang terdiri dari empat tahap yaitu mendefinisikan tujuan bisnis, mendefinisikan business process, mendefinisikan kelas data dan mendefinisikan arsitektur informasi seperti yang diperlihatkan pada gambar 4 .

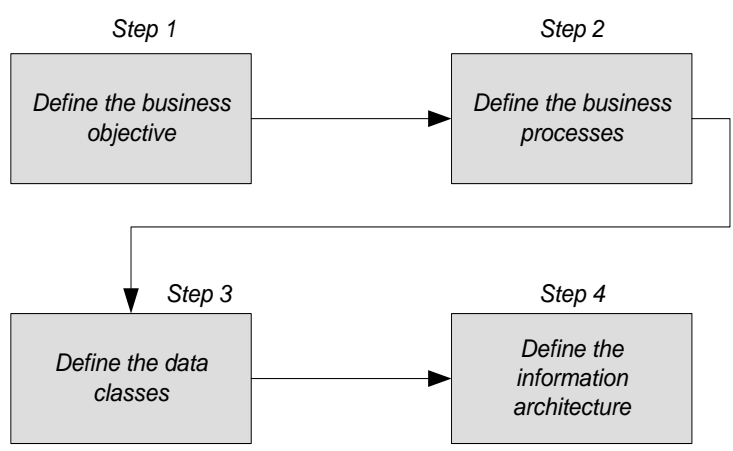

Gambar 4. Pendekatan Perencanaan Sistem Informasi [3]

\section{HASIL DAN PEMBAHASAN}

\section{A. Mendefinisikan tujuan dan sasaran bisnis}

Untuk mendefinisikan tujuan bisnis, digunakan analisis PEST dan SWOT untuk melihat faktor-faktor internal dan eksternal yang mempengaruhi organisasi. Hasil dari analisis PEST dan SWOT akan digunakan untuk mendefinisikan tujuan bisnis Perpusda Kota XYZ. Berikut uraian hasil dari analisis PEST dan SWOT tersebut.

Terdapat 4 aspek yang dilakukan dalam analisis PEST, yaitu:

1. Politik - Kebijakan pemerintah berupa Surat Keputusan Menteri Pendidikan dan Kebudayaan RI No. 0199/0/1978 tanggal 23 Juni 1978, memutuskan untuk meningkatkan peran perpustakaan sebagai sumber belajar seumur hidup.

2. Ekonomi - Krisis ekonomi di Indonesia cukup berdampak dalam kegiatan operasional Perpusda Kota XYZ, yaitu anggaran keuangan dalam mengelola koleksi buku dikurangi, belum ditambah dengan harga buku yang cukup mahal, sehingga pihak perpusda kota XYZ harus melakukan efisiensi dalam tata kelola perpustakaannya.

3. Sosial - Sejalan dengan perkembangan nasional, perkembangan IPTEKS dan semakin meningkatnya minat baca masyarakat kota

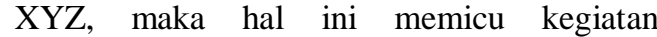
penyelenggaraan perpusda kota XYZ untuk semakin meningkatkan pelayanannya.

4. Teknologi - Sebagai bagian dari organisasi Pemerintah Daerah, perpusda kota XYZ memiliki akses untuk mengikuti perkembangan teknologi, apalagi saat ini Pemerintah Indonesia sedang mempromosikan layanan e-Government kepada masyarakatnya. Hal ini merupakan peluang bagi perpusda kota XYZ karena dengan mengikuti perkembangan teknologi, perpusda kota XYZ dapat meningkatkan layanannya kepada masyarakat.

Analisis SWOT yang dilakukan hanyalah aspek strength dan weakness saja. Aspek threat dan opportunities tidak dilakukan karena sudah terwakili dari analisis PEST. Berikut adalah analisis aspek strength dan weakness:

\section{Strength (kekuatan)}

a. Merupakan pembuat rumusan kebijakan bidang pengelolaan perpustakaan umum dan pengolahan arsip daerah.

b. Mendapat dukungan dari Pemerintah Daerah dalam menjalankan aktivitas bisnisnya.

c. Memiliki berbagai fasilitas layanan seperti: layanan sirkulasi, layanan referensi, audio visual, bercerita, layanan perpustakaan keliling, layanan sistem perpustakaan On-Line.

2. Weakness (kelemahan)

a. Sistem layanan yang dirasa masih lambat karena cukup banyak prosedur-prosedur yang belum efisien dalam menjalankan aktivitas-aktivitas di perpustakaan, baik aktivitas yang dilakukan oleh pegawai 
perpustakaan maupun orang-orang yang memanfaatkan jasa perpusda kota XYZ.

Berdasarkan analisis PEST dan SWOT yang telah dilakukan, tujuan umum Perpusda Kota XYZ adalah:

1. Terwujudnya penyelenggaraan Perpustakaan Daerah sebagai Pusat Kegiatan Belajar masyarakat daerah kota XYZ serta sebagai sarana sumber informasi.

2. Menumbuh kembangkan minat dan budaya baca masyarakat

3. Meningkatkan kualitas Sumber Daya Manusia (SDM) dan kualitas layanan Perpustakan dan Kearsipan.

4. Meningkatkan pembinaan dan pengembangan berbagai jenis perpustakaan.

5. Meningkatkan profesionalisme tenaga pustakawan di kota XYZ.
Perpusda Kota XYZ memiliki visi "Terwujudnya masyarakat dan belajar menuju masyarakat madani yang sadar informasi". Berdasarkan visi Perpusda Kota XYZ, disimpulkan bahwa tujuan utama dari Perpusda Kota XYZ adalah menumbuh kembangkan minat dan budaya baca masyarakat dengan mewujudkan perpustakaan daerah sebagai pusat kegiatan belajar masyarakat. Poin dari tujuan umum lainnya merupakan tujuan sampingan bila ditinjau dari visi organisasi.

Hasil interpretasi tujuan Perpusda Kota XYZ dengan analisis CSF digunakan untuk mendefinisikan sasaran bisnis yang kemudian akan ditentukan aktivitas yang harus dilakukan dan informasi apa yang dibutuhkan. Berikut hasil analisis CSF yang telah dilakukan

Tabel 1. Analisis Critical Success Factor

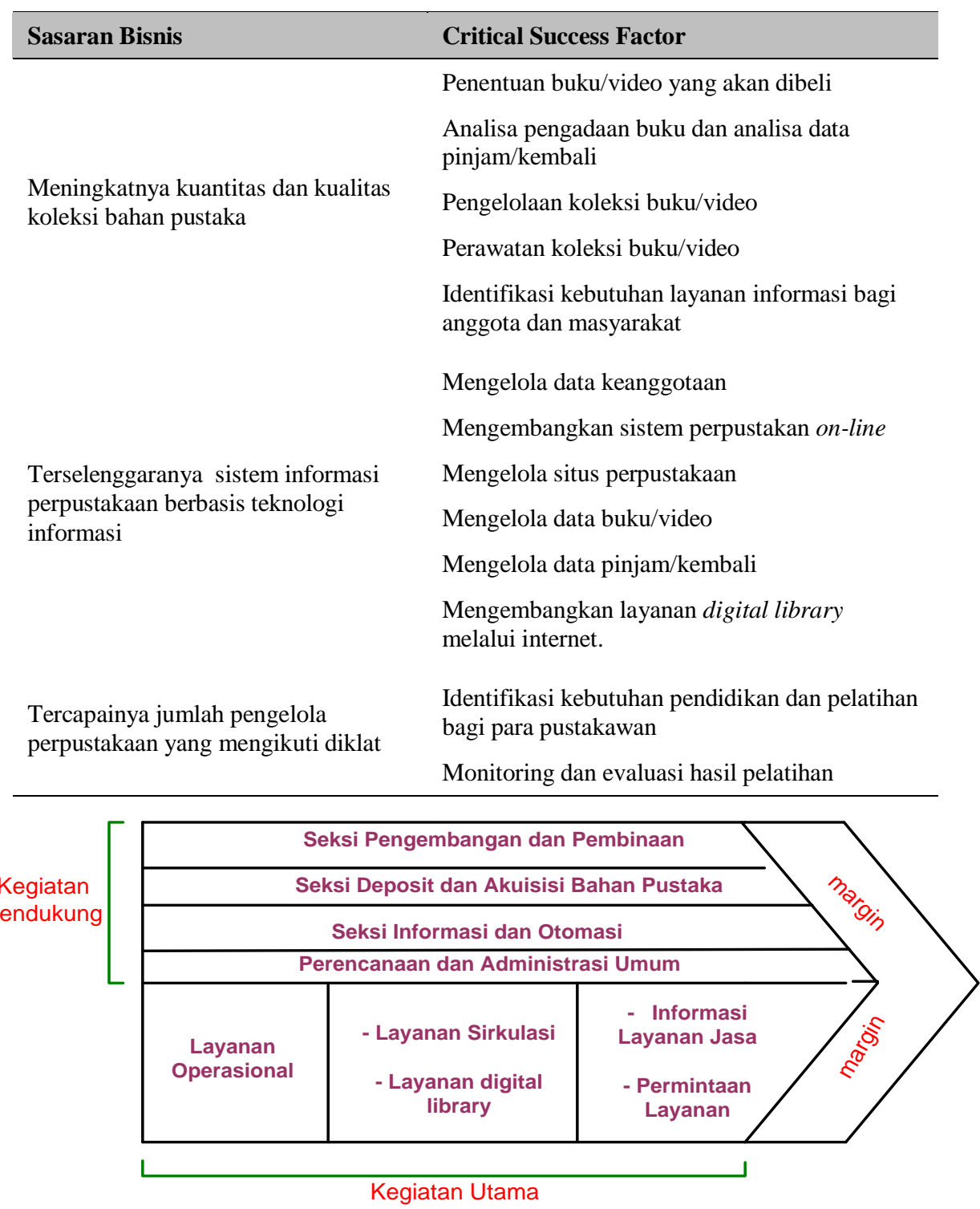

Gambar 5. Value Chain bisnis utama Perpusda Kota XYZ 


\section{B. Mendefinisikan Area Bisnis}

Identifikasi area bisnis yang dilakukan hanyalah identifikasi area bisnis utama dengan menggunakan analisis Value Chain.

Perpusda Kota XYZ memiliki fungsi bisnis utama antara lain: layanan teknis, layanan sirkulasi dan layanan digital library, informasi layanan jasa dan permintaan layanan. Gambar 5 memperlihatkan rantai nilai untuk fungsi bisnis Perpusda Kota XYZ.

Masing-masing kegiatan utama dapat diuraikan sebagai berikut:

a. Layanan operasional, dapat dideskripsikan sebagai kegiatan pengadaan koleksi buku/video dan koleksi khusus (terbitan berkala) dan perawatan buku.

b. Layanan sirkulasi, dapat dideskripsikan sebagai layanan administrasi pinjam/kembali. Sedangkan layanan digital library, dideskripsikan sebagai kegiatan mengolah dokumen mentah menjadi dokumen elektronis sesuai dengan format yang dipakai dan mengelola keanggotaan Perpusda Kota XYZ yang memiliki Account Digital Library.

c. Informasi Layanan Jasa, dapat dideskripsikan sebagai aktivitas yang menyediakan informasi layanan jasa apa saja yang dapat disediakan oleh Perpusda Kota XYZ. Sedangkan permintaan layanan, merupakan aktivitas yang melayani permintaan dari anggota dan non anggota yang terkait dengan proses bisnis Perpusda Kota XYZ.

\section{Mendefinisikan Kelas Data}

Berdasarkan identifikasi proses bisnis, dilakukan identifikasi dan pengelompokkan proses untuk memudahkan analisa terhadap kelas data. Pengelompokan proses yang dilakukan hanya meliputi proses utama saja, yaitu layanan operasional, layanan sirkulasi, layanan digital library, informasi layanan jasa serta permintaan layanan.

Tabel 2. Pengelompokkan Proses

\begin{tabular}{ll}
\hline Layanan Operasional & Layanan Sirkulasi \\
- Perencanaan & - Perencanaan \\
- Pengadaan & - Pengelolaan \\
- Pengolahan & - Peminjaman \\
- Penganggaran & - Pengembalian \\
- Pemeriksaan & - Pelaporan \\
Layanan Digital Library & Informasi Layanan Jasa \\
- Perencanaan & - Perencanaan \\
- Pengelolaan & - Informasi Layanan \\
- Pelaporan & \\
Permintaan Layanan & \\
- Perencanaan & \\
- Peraturan & \\
- Inventarisasi & \\
\hline
\end{tabular}

Dari kelompok proses di atas, dapat dipetakan siklus hidup setiap layanan seperti yang dijelaskan dalam Tabel 3.

Tabel 3. Four Stage Life Cycle Fungsi Bisnis Perpusda Kota XYZ

\begin{tabular}{|c|c|c|c|c|}
\hline $\begin{array}{l}\text { Stage } \\
\text { Fungsi }\end{array}$ & Requirement & Acquisition & Stewardship & Retirement \\
\hline \multirow{2}{*}{$\begin{array}{l}\text { Layanan } \\
\text { Operasional }\end{array}$} & $\begin{array}{l}\text { Perencanaan } \\
\text { Pengadaan } \\
\text { dan } \\
\text { Pengolahan } \\
\text { Buku }\end{array}$ & $\begin{array}{l}\text { Menerima } \\
\text { usulan buku }\end{array}$ & $\begin{array}{l}\text { Memeriksa buku } \\
\text { yang diusulkan }\end{array}$ & $\begin{array}{l}\text { Menerima dan } \\
\text { memvalidasi } \\
\text { buku yang } \\
\text { dipesan }\end{array}$ \\
\hline & $\begin{array}{l}\text { Perencanaan } \\
\text { Pengadaan } \\
\text { Terbitan } \\
\text { Berkala }\end{array}$ & $\begin{array}{l}\text { Penetapan } \\
\text { Anggaran }\end{array}$ & $\begin{array}{l}\text { Memeriksa kartu } \\
\text { indeks terbitan } \\
\text { berkala } \\
\text { Mengubah status } \\
\text { kartu indeks }\end{array}$ & $\begin{array}{l}\text { Menerima dan } \\
\text { memvalidasi } \\
\text { terbitan berkala } \\
\text { yang dipesan }\end{array}$ \\
\hline $\begin{array}{l}\text { Layanan } \\
\text { Sirkulasi }\end{array}$ & $\begin{array}{l}\text { Perencanaan } \\
\text { Pengelolaan } \\
\text { Koleksi Buku }\end{array}$ & $\begin{array}{l}\text { Penetapan } \\
\text { kebijakan } \\
\text { pengelolaan }\end{array}$ & $\begin{array}{l}\text { Pelaksanaan } \\
\text { administrasi } \\
\text { pinjam/kembali }\end{array}$ & $\begin{array}{l}\text { Pelaporan } \\
\text { pinjam/kembali }\end{array}$ \\
\hline & & $\begin{array}{l}\text { Tata tertib } \\
\text { keanggotaan }\end{array}$ & & \\
\hline $\begin{array}{l}\text { Layanan } \\
\text { Digital } \\
\text { Library }\end{array}$ & $\begin{array}{l}\text { Perencanaan } \\
\text { Pengelolaan } \\
\text { Dokumen } \\
\text { Mentah }\end{array}$ & $\begin{array}{l}\text { Penetapan } \\
\text { kebijakan } \\
\text { pengelolaan } \\
\text { keanggotaan }\end{array}$ & $\begin{array}{l}\text { Mengelola dan } \\
\text { mengembangkan } \\
\text { situs Perpusda } \\
\text { Kota XYZ }\end{array}$ & $\begin{array}{l}\text { Pelaporan } \\
\text { pemberitahuan } \\
\text { account pada } \\
\text { anggota }\end{array}$ \\
\hline $\begin{array}{l}\text { Informasi } \\
\text { Layanan } \\
\text { Jasa }\end{array}$ & $\begin{array}{l}\text { Perencanaan } \\
\text { Layanan } \\
\text { Informasi }\end{array}$ & $\begin{array}{l}\text { Format } \\
\text { Layanan } \\
\text { yang } \\
\text { disediakan }\end{array}$ & $\begin{array}{l}\text { Paket Perangkat } \\
\text { Lunak }\end{array}$ & $\begin{array}{l}\text { Informasi } \\
\text { Layanan }\end{array}$ \\
\hline $\begin{array}{l}\text { Permintaan } \\
\text { Layanan }\end{array}$ & $\begin{array}{l}\text { Perencanaan } \\
\text { Layanan } \\
\text { yang } \\
\text { diberikan }\end{array}$ & $\begin{array}{l}\text { Tata cara } \\
\text { permintaan } \\
\text { layanan }\end{array}$ & $\begin{array}{l}\text { Inventarisasi } \\
\text { permintaan } \\
\text { layanan }\end{array}$ & $\begin{array}{l}\text { Daftar layanan } \\
\text { yang dipesan }\end{array}$ \\
\hline
\end{tabular}




\section{Analisa Sistem dan Teknologi Saat Ini}

Sistem informasi yang ada pada Perpusda Kota XYZ saat ini merupakan sistem informasi yang digunakan untuk mendukung kegiatan operasional sehari-hari, seperti pencatatan buku yang dipinjam dan yang dikembalikan, mencatat buku yang harus dibeli, dan lain sebagainya.

Tabel 4 menggambarkan koleksi aplikasi dan pengolahan data yang saat ini ada dan digunakan oleh Perpusda Kota XYZ.

Tabel 4. Koleksi Aplikasi dan Pengolahan Data

\begin{tabular}{ll}
\hline $\begin{array}{l}\text { Aplikasi/Pengolahan } \\
\text { Data }\end{array}$ & Keterangan \\
\hline Layanan Operasional & $\begin{array}{l}\text { Berbentuk aplikasi perangkat } \\
\text { lunak dan sebagian } \\
\text { menggunakan spreadsheet }\end{array}$ \\
& $\begin{array}{l}\text { Berbentuk aplikasi perangkat } \\
\text { lunak koleksi perpustakaan } \\
\text { dan transaksi pinjam/kembali, } \\
\text { denda serta keanggotan }\end{array}$ \\
Layanan Sirkulasi & $\begin{array}{l}\text { Berbentuk aplikasi perangkat } \\
\text { lunak keanggotaan digital } \\
\text { library dan informasi } \\
\text { buku/video }\end{array}$ \\
\hline
\end{tabular}

Adapun fungsi bisnis yang telah didukung oleh penggunaan aplikasi dapat dilihat dalam tabel 5 .

Tabel 5. Tabel fungsi yang didukung aplikasi

\begin{tabular}{|c|c|}
\hline Nama Fungsi & Deksripsi Fungsi \\
\hline \multirow{2}{*}{ Layanan Operasional } & $\begin{array}{l}\text { Pencatatan koleksi } \\
\text { buku/video }\end{array}$ \\
\hline & $\begin{array}{l}\text { Pencatatan semua koleksi } \\
\text { terbitan berkala }\end{array}$ \\
\hline \multirow{5}{*}{ Layanan Sirkulasi } & Pencatatan data keanggotaan \\
\hline & $\begin{array}{l}\text { Pencatatan data pinjam dan } \\
\text { kembali }\end{array}$ \\
\hline & Pencatatan denda pinjaman \\
\hline & $\begin{array}{l}\text { Pelaporan data pinjam dan } \\
\text { kembali }\end{array}$ \\
\hline & $\begin{array}{l}\text { Pencatatan koleksi } \\
\text { buku/video }\end{array}$ \\
\hline \multirow{4}{*}{ Layanan Digital Library } & $\begin{array}{l}\text { Pencatatan dan penyimpanan } \\
\text { data-data digitalisasi }\end{array}$ \\
\hline & Pelaporan koleksi digitalisasi \\
\hline & $\begin{array}{l}\text { Pencatatan keanggotaan } \\
\text { digitalisasi }\end{array}$ \\
\hline & $\begin{array}{l}\text { Pencatatan koleksi } \\
\text { buku/video }\end{array}$ \\
\hline
\end{tabular}

Kelemahan utama dari sistem informasi yang ada saat ini adalah belum terintegrasinya aplikasi layanan sistem informasi yang ada saat ini. Masing-masing aplikasi/pengolahan data tersebut harus memiliki basis datanya sendiri-sendiri, padahal data yang digunakan sebenarnya adalah data yang sama. Akibatnya, terdapat redundansi data. Keadaan ini berpengaruh pada prosedur-prosedur aktivitas bisnis yang terlibat.

\section{E. Arsitektur Sistem Informasi}

Berdasarkan analisis dan identifikasi yang telah dilakukan sebelumnya, kemudian dilakukan identifikasi beberapa subsistem dari setiap kelompok informasi dengan mempertimbangkan hasil analisis critical success factor serta hasil analisis sistem dan teknologi yang ada untuk memetakan kebutuhan informasi yang diperlukan. Identifikasi terhadap subsistem diperlukan untuk memperjelas ruang lingkup suatu kelompok informasi, yang akan dituangkan dalam portofolio aplikasi seperti yang terlihat pada tabel 6 .

Strategic, adalah sistem informasi yang secara signifikan memiliki nilai strategis bagi organisasi, tanpa sistem informasi ini, maka organisasi akan kalah bersaing dengan organisasi lainnya. Sistem yang masuk dalam posisi strategis adalah Sistem Analisis Pengadaan Buku serta Sistem Analisis Sirkulasi Bahan Pustaka (pinjam/kembali).

Sistem Informasi Layanan Digital Library, Sistem Informasi Perpustakaan On Line serta Sistem Informasi e-Procurement memberikan nilai high potential yang artinya komponen tersebut memberikan keunggulan kompetitif langsung kepada Perpusda Kota XYZ, namun secara prinsip eksistensi Perpusda tidak tergantung dari komponen tersebut.

Key Operational, merupakan sistem informasi yang tidak secara langsung memberikan keuntungan kompetitif kepada organisasi namun keberadaannya mutlak diperlukan. Hasil analisis sistem dan teknologi yang ada, fungsi bisnis yang didukung oleh aplikasi masuk dalam kategori ini, seperti sistem administrasi pinjam/kembali, sistem administrasi pengadaan buku/CD, dan lain sebagainya yang telah dijelaskan dalam Tabel 5. Fungsi bisnis yang telah ditunjang oleh aplikasi saat ini, kebanyakan masih berupa pencatatan koleksi bahan pustaka dan masih memerlukan pengembangan lebih lanjut serta belum terintegrasi.

Support, merupakan sistem informasi yang hanya berfungsi sebagai penunjang organisasi dan tidak memiliki potensi yang besar dalam memberikan keunggulan kompetitif organisasi.

Tabel 6. Portofolio Aplikasi Perpusda Kota XYZ

STRATEGIC HIGH POTENTIAL

Sistem Informasi Analisis Pengadaan Buku ${ }^{@}$

Sistem Informasi Layanan

Sistem Informasi Analisis Pinjam/ Kembali ${ }^{@}$

Digital Library ${ }^{\circledR}$

Sistem Informasi e-

Procurement ${ }^{\circledR}$

Sistem Informasi

Perpustakaan OnLine ${ }^{\circledR}$

\section{KEY OPERATIONAL SUPPORT}

Sistem Administrasi 
Pinjam/Kembali ${ }^{*}$

Sistem Administrasi Pengadaan Buku/Video*

Sistem Pencatatan Koleksi Buku/ Video*

Sistem Pencatatan Denda Pinjamam*

Sistem Pelaporan Koleksi Buku /Video

Sistem Pelaporan Pinjam/Kembali"

Sistem pencatatan dan penyimpanan data digitalisasi $^{\#}$

Sistem Administrasi Keanggotaan

Sistem Administrasi Keanggotaan Digital Library"

Sistem Pelaporan Data Digitalisasi

Sistem Pencatatan Terbitan Berkala ${ }^{*}$
Pelatihan dan Pendidikan Pustakawan $^{@}$

Sistem Pengendalian ATK, Sarana dan Prasarana ${ }^{@}$
Sistem Pelaporan Terbitan

Berkala $^{\#}$

Sistem ERP ${ }^{@}$

\section{Keterangan}

- $\quad$ * sistem yang sudah berjalan

- \# sistem berjalan yang masih butuh pengembangan

- @ sistem yang direncanakan

\section{F. Penentuan Prioritas Implementasi}

Berdasarkan portofolio aplikasi yang telah dihasilkan, akan dilakukan identifikasi dari setiap pengelompokan sistem informasi. Untuk setiap sistem berjalan yang masih butuh pengembangan serta sistem yang direncanakan, dilakukan identifikasi skala prioritas berdasarkan potential benefit, impact, success, dan demand, dengan menggunakan pertimbangan sebagai berikut:

a. Keadaan operasional bisnis yang saat ini ada di perusahaan

b. Tujuan bisnis perusahaan

c. Ketersediaan data

Hasil penilaian penentuan prioritas pengembangan sistem terlihat pada tabel 7 dengan skala maksimum $\begin{array}{lll}\text { masing-masing } & \text { kriteria } & \end{array}$

Tabel 7. Penentuan Prioritas Pengembangan Sistem

\begin{tabular}{|c|c|c|c|c|c|c|}
\hline Sistem & Subsistem & $\begin{array}{l}\text { Potensial } \\
\text { Benefit }\end{array}$ & Impact & Succes & Demand & Total Score \\
\hline \multirow[t]{2}{*}{ Strategic } & SI analisis pengadaan buka & 20 & 20 & 20 & 20 & 80 \\
\hline & SI analisis pinjam/kembali & 20 & 20 & 20 & 20 & 80 \\
\hline \multirow[t]{3}{*}{ High Potensial } & SI layanan digital library & 15 & 15 & 15 & 20 & 65 \\
\hline & SI e-procurement & 15 & 10 & 10 & 5 & 30 \\
\hline & SI perpustakaan online & 20 & 20 & 20 & 20 & 80 \\
\hline \multirow[t]{2}{*}{ Support } & $\begin{array}{l}\text { Sistem manajeman pelatihan dan } \\
\text { pendidikan pustakawan }\end{array}$ & 10 & 5 & 5 & 10 & 30 \\
\hline & $\begin{array}{l}\text { Sistem pengendalian ATK, sarana } \\
\text { dan prasarana }\end{array}$ & 15 & 10 & 10 & 10 & 45 \\
\hline \multirow[t]{4}{*}{$\begin{array}{l}\text { Key } \\
\text { Operational }\end{array}$} & $\begin{array}{l}\text { Sistem pencatatan dan penyimpanan } \\
\text { data digitalisasi }\end{array}$ & 20 & 20 & 15 & 20 & 75 \\
\hline & Sistem pelaporan data digitalisasi & 20 & 20 & 20 & 10 & 70 \\
\hline & Sistem pelaporan terbitan berkala & 20 & 20 & 20 & 20 & 80 \\
\hline & Sistem ERP & 20 & 20 & 20 & 20 & 80 \\
\hline
\end{tabular}

Berdasarkan penskalaan prioritas, subsistem informasi yang mendapatkan prioritas sesuai urutan adalah sebagai berikut:

1. Sistem Informasi Analisis Pengadaan Buku

2. Sistem Informasi Analisis Pinjam/Kembali

3. Sistem Informasi Perpustakaan OnLine

4. Sistem Pelaporan Terbitan Berkala

5. Sistem ERP

Apabila dilihat hasil pengurutan prioritas, maka hal tersebut sudah sesuai dengan tujuan Perpusda Kota $\mathrm{XYZ}$ yaitu menumbuh kembangkan minat dan budaya baca masyarakat dengan mewujudkan perpustakaan daerah sebagai pusat kegiatan belajar masyarakat.

\section{KESIMPULAN DAN SARAN}

\section{A. Kesimpulan}

Dari seluruh tahapan pengerjaan yang telah dilakukan, maka dapat sisimpulkan:Perencanaan strategi pengembangan sistem informasi merupakan suatu langkah yang pada dasarnya memerlukan waktu dan proses untuk memenuhi hasil akhir yang diinginkan.

1. Perencanaan strategi pengembangan sistem informasi, membutuhkan keterlibatan pihak manajemen, karena dalam proses perencanaan dibutuhkan suatu pemikiran yang strategis. 
2. Perencanaan strategi pengembangan sistem informasi dalam organisasi perlu untuk dilakukan agar dalam proses pengembangan sistem informasi kedepannya dapat terarah, sehingga proses bisnis yang dilakukan dapat lebih efektif dan memenuhi sasaran organisasi.

3. BSP dapat dijadikan alternative dalam menganalisa keadaan bisnis yang sedang berlangsung dan dapat dijadikan landasan pemikiran pada perancangan arsitektur informasi perusahaan.

\section{B. Saran}

Perlu dikembangkan lebih lanjut terhadap penelitian mengenai tools atau kakas lainnya yang dapat digunakan dengan efektif dalam melakukan analisis portofolio aplikasi khususnya bagi organisasi nirlaba.

\section{DAFTAR PUSTAKA}

[1] Ward, Jhon and Pepard, Joe, "Strategic Planning for Information Systems", John Wiley \& Sons, Inc, 2002.

[2] Porter, Michael, E, "Competitive Advantage Creating Sustaining Superior Performance", New York:The Free Press. 1985.

[3] IBM, Business Systems Planning (Information System Planning Guide) International Business Machines Corporation, 1981. 